Daniela von Ah Lopes1, Marcelo Araújo do Valle ${ }^{2}$, Jéfferson Taguti ${ }^{3}$, Regina Celli Thomé Castro Tagutí, Gustavo Navarro Betônico5 ${ }^{5}$ Fabiana Clemente Medeiros ${ }^{6}$

1. Médica da Unidade de Terapia Intensiva do Hospital IAMADA Presidente Prudente (SP), Brasil.

2. Médico intensivista chefe da Unidade de Terapia Intensiva do Hospital IAMADA - Presidente Prudente (SP), Brasil.

3. Médico do Serviço de Cirurgia do Hospital IAMADA - Presidente

Prudente (SP), Brasil

4. Médica do Serviço de

Gastroenterologia do Hospital

IAMADA - Presidente Prudente (SP),

Brasil.

5. Médico da Unidade de Terapia Intensiva do Hospital IAMADA Presidente Prudente (SP), Brasil.

6. Nutricionista do Serviço de Nutriçáo e Dietética e da Equipe Multidisciplinar de Terapia Nutricional do Hospital IAMADA - Presidente Prudente (SP), Brasil.

Recebido da Unidade de Terapia Intensiva do Hospital IAMADA Presidente Prudente (SP), Brasil.

Submetido em 3 de Julho de 2008

Aceito em 12 de Dezembro de 2008

Autor para correspondência:

Daniela von Ah Lopes

Rua Bandeirante René Nobre, 652

Bairro Jardim Bongiovani.

CEP 19050-430 Presidente Prudente

(SP), Brasil.

Fone: 018 - 39087542

E-mail: dolgado@itelefonica.com.br

\section{Porfiria aguda intermitente: relato de caso e revisáo da literatura}

\author{
Acute intermittent porphyria: case report \\ and review of the literature
}

\section{RESUMO}

Porfiria aguda intermitente é patologia incomum, com conseqüências potencialmente graves se não reconhecida precocemente. Dentre as possíveis causas de induçấo de crises de porfiria, a reduçáo da ingestão calórica é descrita na literatura. Relatamos um caso de porfiria aguda intermitente no pós-operatório tardio de gastroplastia indicada para tratamento da obesidade, revisando aspectos do diagnóstico e tratamento da patologia na unidade de terapia intensiva. Paciente feminina, 31 anos, com história de gastroplastia há 3 semanas admitida na unidade de terapia intensiva com rebaixamento do nível de consciência e desconforto respiratório. Evoluiu com agitaçáo psicomotora, confusão mental, dor abdominal e tetraparesia proximal. $\mathrm{Na}$ investigação diagnóstica foi encontrado hiponatremia grave (92 $\mathrm{mEq} / \mathrm{L}$ ), hipomagnesemia, hipofosfatemia e hipocalcemia, urina turva, sem hematúria. Aventou-se hipótese de porfiria aguda, realizado dosagem do ácido delta-aminolevulínico e porfobilinogênio na urina de $24 \mathrm{~h}$, com elevação de ambos.
Iniciado tratamento com dieta rica em carboidratos, sem utilizar hematina ou arginato de heme, devido à dificuldades no fornecimento destas medicaçôes. Evoluiu com melhora clínica gradativa e recuperação completa da força muscular após 8 meses. A porfiria aguda intermitente possui sinais e sintomas comuns a muitas patologias clínicas e neuropsiquiátricas dificultando o diagnóstico, em especial quando estes se manifestam isoladamente. Assim, deve-se incluir a porfiria aguda intermitente no diagnóstico diferencial de distúrbios neurológicos, psiquiátricos e gastroenterológicos em crises, no qual todos os demais exames estejam normais. Atenção deve ser dada a pacientes submetidos à cirurgias, em especial cirurgia bariátrica que, além do estresse cirúrgico, limita substancialmente a ingesta calórica podendo desencadear crises. Não há descrito na literatura, até o momento, nenhum caso de porfiria aguda intermitente no pós-operatório de cirurgia bariátrica.

Descritores: Porfiria aguda intermitente/diagnóstico; Hiponatremia; Cirurgia bariátrica

\section{INTRODUÇÃO}

A porfiria aguda intermitente (PAI) é uma doença genética rara, autossômica dominante, decorrente de um distúrbio na via hepática da biossíntese do heme, causado pela redução dos níveis da enzima porfobilinogênio desaminase (PBG-D). Caracteriza-se por sinais e sintomas, geralmente intermitentes, que incluem dor abdominal, náuseas, vômitos, constipação ou diarréia, distensão abdominal, íleo adinâmico, retenção ou incontinência urinárias, taquicardia, sudorese, tremores, febre, neuropatia periférica, distúrbios hidroeletrolíticos e psiquiátricos (Quadro 1). Existem muitos fatores que podem precipitar uma 
crise de PAI, entre estes destaca-se a dieta hipocalórica e pobre em carboidratos. Em relação ao tratamento da obesidade mórbida, vale salientar que, todos os procedimentos cirúrgicos utilizados (restritivo, disabsortivo ou misto) são passíveis de desencadear crise de PAI em função da restrição dietética a que os pacientes são submetidos no pós-operatório. A dor abdominal é o sintoma mais característico e geralmente o mais precoce, sendo difusa e possivelmente acompanhada por náuseas e vômitos. Este quadro clínico é comum em pós-operatórios de cirurgias abdominais, porém, nos casos de PAI, a dor frequentemente é de forte intensidade e não responde a analgésicos usuais que, quando utilizados, podem piorar a crise. Além disso, outros sinais e sintomas como fraqueza muscular, confusão mental e alucinaçóes podem direcionar para o diagnóstico de acordo com o contexto clínico. Incluir PAI no diagnóstico diferencial de distúrbios neurológicos, psiquiátricos e gastroenterológicos em crises, no qual todos os demais exames estejam normais, contribui para aumentar a chance diagnóstica bem como adequar o tratamento.

Quadro 1. Sinais e sintomas freqüentes em porfiria aguda

\begin{tabular}{|lc|}
\hline Sinais e sintomas & Incidência estimada (\%) \\
\hline Gastrointestinais & \\
Dor abdominal & $85-95$ \\
Vômito & $43-88$ \\
Constipacão intestinal & $48-84$ \\
Diarréia & $5-12$ \\
Neurológicos & \\
Sintomas álgicos inespecíficos & $50-70$ \\
Paresia & $42-68$ \\
Paralisia respiratória & $9-20$ \\
Sintomas psiquiátricos & $40-58$ \\
Convulsão & $10-20$ \\
Cardiovascular & \\
Taquicardia & $28,64-85$ \\
Hipertensão arterial sistêmica & $36-55$ \\
\hline
\end{tabular}

Baseado em série de pacientes com porfiria aguda intermitente sintomática ${ }^{5}$

Fonte: Traduzido e adaptado de: Anderson KE, Bloomer JR, Bonkovsky HL, Kushner JP, Pierach CA, Pimstone NR, Desnick RJ. Recommendations for the diagnosis and treatment of the acute porphyrias. Ann Intern Med. 2005;142(6):439-50. Erratum in: Ann Intern Med. 2005;143(4):316.

O diagnóstico baseia-se na excreção urinária elevada dos precursores das porfirinas: ácido delta-aminolevulínico (ALA) e porfobilinogênio (PBG). Macroscopicamente, o acúmulo destes precursores excretados na urina pode mudar sua cor, após exposição ao sol, do amarelado para um vermelho ou marrom escuros, ocasionalmente até um tom de púrpura. Laboratorialmente, um valor muito elevado de PBG na urina de 24 h é diagnóstico da presença de porfiria aguda. O tratamento das crises de PAI consiste em tratar os sintomas com drogas consideradas seguras, suspender medicamentos porfirinogênicos, fornecer um aporte elevado de glicose, utilizar hematina ou arginato do heme de acordo com a gravidade do quadro.

O caso abaixo justifica seu relato, pois a apresentação clínica de porfiria aguda intermitente desencadeada por dieta restritiva no pós-operatório tardio de cirurgia bariátrica não foi encontrada na literatura.

\section{RELATO DO CASO}

Paciente do sexo feminino, 31 anos, branca, deu entrada na unidade de terapia intensiva do Hospital Iamada, em Presidente Prudente (SP), com quadro de rebaixamento do nível de consciência e desconforto respiratório há 12 horas. Havia sido admitida neste hospital sete dias antes, com quadro de dor abdominal e lombar de forte intensidade; associada a náuseas, vômitos e inapetência. $\mathrm{Na}$ enfermaria evoluiu com agitação psicomotora, confusão mental e alucinaçōes. Ao exame físico apresentava-se torporosa, confusa, atendendo a solicitaçóes verbais, desidratada $(++/ 4+)$, taquicárdica (136bpm), taquipneica (36irpm), hipertensa $(180 \times 100 \mathrm{mmHg})$ com abdome globoso, flácido, ruídos hidroaéreos presentes, difusamente doloroso a palpação superficial e profunda, com massa palpável no hipogástrio, dolorosa, não pulsátil. Havia tetraparesia proximal com tônus muscular preservado, reflexos tendinosos lentificados, reflexo cutâneo plantar em flexão, pupilas midriáticas, porém isocóricas e fotorreagentes.

Havia história pregressa de cirurgia bariátrica (gastroplastia com derivação intestinal) há 3 semanas, ocorrida sem intercorrências no pós-operatório precoce e não havia outros antecedentes ou fatores de comorbidade. Após a sondagem vesical, instituída na admissão da UTI, foram obtidos $2.000 \mathrm{ml}$ de urina vermelho escura. Diante da gravidade do quadro foram instauradas medidas de suporte com oxigênio inalatório por máscara e reposição volêmica. Os exames laboratoriais na admissão mostraram hiponatremia grave $(92 \mathrm{mEq} / \mathrm{L})$ acompanhada de hipomagnesemia $(0,4 \mathrm{mEq} / \mathrm{L})$, hipofosfatemia $(1,7 \mathrm{mg} / \mathrm{dL})$ e hipocalcemia $(0,86 \mathrm{mmol} / \mathrm{L})$. Outros exames como: potássio, creatinina, hemograma, amilase, provas de função reumática e tiroidiana mostraram resultados normais. Havia elevação discreta dos níveis séricos das transaminases hepáticas; urina de cor amarelo-escura, aspecto turvo, porém com ausência de hematúria no exame de urina I; proteína $\mathrm{C}$ reativa (PCR) levemente elevada; eletroforese de proteínas 
sem alteraçóes; hemocultura e urocultura negativas. Exames de imagem (radiografia de tórax, abdome e trânsito intestinal; ultrasonografia de abdome; tomografia de abdome e coluna lombar; ressonância nuclear magnética de crânio) sem alteraçóes. A endoscopia digestiva alta revelou a presença de lesôes ulceradas na alça eferente, sem sinais de sangramento. Iniciada a correção da hiponatremia, na velocidade segura, com solução salina a 3\% apresentando normalização do sódio em 5 dias (Figura 1).

\section{Evolução dos valores do sódio sérico}

Valor inicial de admissão: $92 \mathrm{mEq}$.

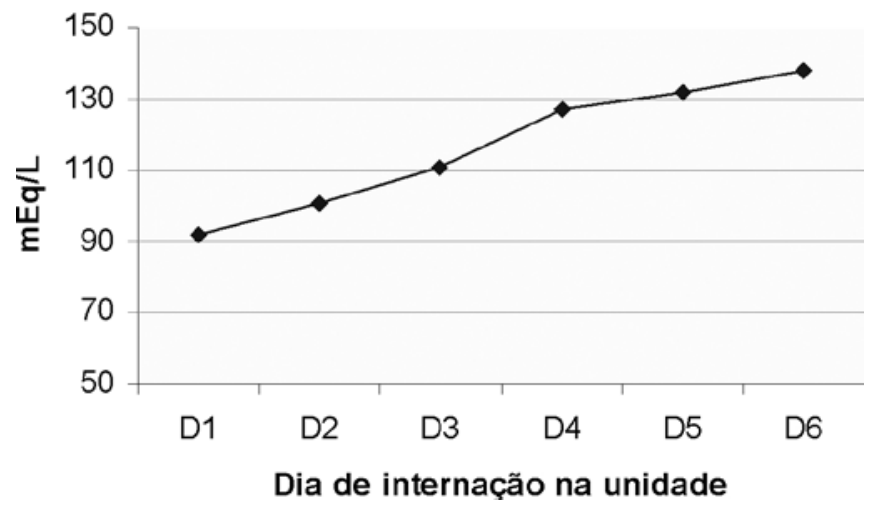

Figura 1 - Velocidade de correçáo da hiponatremia.

Com base nos achados clínicos e de exames complementares, aventou-se a hipótese de porfiria aguda três dias após a internação na UTI, sendo então realizado dosagem do acido delta-aminolevulínico e porfobilinogênio na urina de $24 \mathrm{~h}$ com elevaçáo significativa de ambos (ácido delta aminolevulínico: $15 \mathrm{mg} / 24 \mathrm{~h}$ - ref.: 1,3 a $7,0 \mathrm{mg} / 24 \mathrm{~h}$; porfobilinogênio: $4,25 \mathrm{mg} / 24 \mathrm{~h}$ - ref. 1,0 a $1,5 \mathrm{mg} / 24 \mathrm{~h}$ ). Confirmando-se o diagnóstico foi prontamente instituído o tratamento com dieta rica em carboidratos: dieta enteral através da gastrostomia, em gotejamento contínuo, $60 \mathrm{ml} / \mathrm{h}$ em 20 horas sendo hipercalórica (2370 calorias), hipoproteica (35,55 g de proteínas), hiperlipídica (113,28 $\mathrm{g}$ de lipídeos) e rica em carboidratos $(302,41 \mathrm{~g})$. Associado a isto, foi utilizado módulo de carboidratos $(100 \%$ oligossacarídeos - maltodextrina) $72 \mathrm{~g} /$ dia para completar a recomendação estabelecida para PAI (300 a 400 g/dia), totalizando $374,41 \mathrm{~g}$ de carboidratos por dia. Concomitantemente, a paciente se alimentava por via oral em pequenas quantidades seguindo o protocolo de orientação nutricional pós gastroplastia com quantidades reduzidas de açúcares para que não ocorresse a síndrome de dumping induzida pelo desvio intestinal feito na cirurgia bariátrica. Não foi possível iniciar terapêutica específica com hematina ou arginato de heme por dificuldade de obten- ção destes medicamentos no Brasil. A paciente evoluiu com melhora clínica gradativa e recebeu alta da UTI após 15 dias da internação, consciente, orientada, sem sinais de mielinólise pontina ou extra-pontina, porém ainda com redução da força muscular. $\mathrm{Na}$ unidade de internação a conduta nutricional se manteve a mesma durante todo o período. Passadas duas semanas, recebeu alta hospitalar com a seguinte orientação dietoterápica: 1) via oral: dieta branda, sucos de frutas náo ácidas e vitamina com leite semi-desnatado a cada 2 horas, na quantidade que a paciente tolerasse com redução de carboidratos simples, para não ocorrer a síndrome de dumping; 2) via gastrostomia: dieta industrializada hipercalórica, nutricionalmente completa pronta para uso e dieta artesanal rica em carboidratos de alto índice glicêmico administrada em gotejamento gravitacional intermitente a cada 3 horas, com pausa durante a noite. $\mathrm{O}$ acompanhamento nutricional teve continuidade em âmbito ambulatorial, até que fosse possível a retirada da alimentação através da sonda de gastrostomia e ingestão, por via oral, dos suprimentos calórico, protéico e vitamínico-mineral necessários para o bem estar clínico da paciente. Houve recuperação completa da força muscular após 8 meses do evento agudo.

\section{DISCUSSÃO}

A porfiria aguda intermitente compóe um grupo de pelo menos oito doenças genéticas distintas, além de formas adquiridas, conhecidas como porfirias. Estima-se sua ocorrência em 1 a 2 pessoas a cada 100.000 , sendo a incidência mais comum em países do norte da Europa como Inglaterra, Irlanda e Suécia (onde chega a 1:10.000). ${ }^{(1)}$ Em portadores de doenças psiquiátricas a literatura cita prevalência de até $1: 500 .^{(2)}$ A PAI é a principal porfiria que causa sintomas agudos, que podem ser severos e com risco de vida, mas de curta duração. Tipicamente, as crises de PAI ocorrem após a puberdade e são mais freqüentes em mulheres do que em homens. ${ }^{(3)}$

Em condiçôes normais, a deficiência da enzima não é suficiente para iniciar as crises. Sáo necessários outros fatores para induzir os sintomas, assim, cerca de $80 \%$ dos portadores de deficiência da atividade enzimática jamais chegam a apresentar qualquer sintoma (chamados de indivíduos com PAI "latente") e parte dos restantes sofrem apenas sintomas leves ocasionais. ${ }^{(4)}$ Fatores ambientais desempenham papel importante no desencadeamento e curso desta doença. Muitos medicamentos (barbitúricos, anticonvulsivantes, bloqueadores dos canais de cálcio, alguns sedativos, antibióticos, antifúngicos e hormônios) podem desencadear os sintomas, assim como o consumo de grandes quantidades de 
bebidas alcoólicas, tabaco ou dietas hipocalóricas e pobres em carboidratos. $\mathrm{O}$ estresse como resultado de infecçáo, outra eventual doença concomitante, cirurgia ou distúrbio psicológico também é algumas vezes implicado na gênese da crise de porfiria. A dor abdominal é o sintoma mais característico e geralmente o mais precoce. Com freqüência é de forte intensidade, localizada difusamente pelo abdome, e não responde a analgésicos usuais, que quando utilizados ainda podem piorar a crise. Concomitante à dor, podem ocorrer náuseas, vômitos, constipação, retenção urinária, arritmias, hiper ou hipotensão, além de distúrbios hidroeletrolíticos, notadamente a hiponatremia. ${ }^{(1,5)}$ Esta pode ser secundária a um conjunto de fatores como diarréia, vômitos, baixa ingesta e em especial, perda renal excessiva e secreção inapropriada do hormônio antidiurético $(\mathrm{ADH})$. Sintomas de neuropatia periférica incluem fraqueza muscular em membros superiores e inferiores, alteraçóes de sensibilidade, podendo haver neuropatia motora dos nervos cranianos (levando a sintomas como dislalia, disfagia, diplopia e paralisia facial). $\mathrm{O}$ acometimento mais severo do sistema nervoso central pode levar a convulsóes e até a paralisia bulbar, com falência respiratória e morte. Achados psiquiátricos incluem histeria, ansiedade, apatia ou depressão, fobias, psicose, agitação, delirium, sonolência ou coma. ${ }^{(1)}$

No caso relatado, a paciente apresentou todos os principais sinais e sintomas, bem como os mais graves: dor abdominal de forte intensidade, hiponatremia severa, hipertensão arterial, insuficiência respiratória e distúrbio psiquiátrico. Provavelmente o principal fator desencadeante da crise foi a dieta hipocalórica e pobre em carboidratos imposta pela cirurgia, mas outros fatores como medicamentos, utilizados antes do diagnóstico específico, podem ter contribuído para agravar o processo. Devemos ter em mente que inúmeras condiçóes e procedimentos cirúrgicos que acarretam restrição dietética como as gastrectomias e cirurgias intestinais podem precipitar crise de PAI que, possivelmente, estão sendo subdiagnosticadas. A atenção para os quadros de dor abdominal em crises que não condizem com o quadro clínico esperado para o pósoperatório em questáo, bem como aos sintomas acompanhantes, podem contribuir para o diagnóstico precoce.

Os sintomas manifestados pela paciente desde sua admisão no hospital, quando analisados isoladamente, podem mimetizar diversas doenças do sistema digestivo e neuropsiquiátricas. Assim, é sabido que o diagnóstico de porfiria, mesmo em pacientes com crises severas, usualmente é difícil e pode só ser realizado depois de meses de acompanhamento e várias crises. Precocemente, pode-se aventar a hipótese diagnóstica de PAI quando há histórico familiar da doença ou se houver alto índice de suspeição.
O primeiro passo no diagnóstico da PAI é a dosagem urinária, nas crises, de ALA e de PBG. A excreção urinária de ALA, em pessoas normais, costuma ser abaixo de $7 \mathrm{mg}$ e a de PBG de $2 \mathrm{mg}$ em 24 horas. Nas crises, a quantidade excretada de ambos pode ser várias vezes esse valor e mesmo fora das crises, o valor de ambos pode estar elevado, o que permite o diagnóstico de PAI latente em parentes próximos de um portador de PAI sintomática. ${ }^{(4)} \mathrm{A}$ medida da atividade da enzima PBG deaminase (ou HMB sintase) nas hemácias é suficiente para confirmar o diagnóstico de PAI em 95\% dos casos. ${ }^{(1)}$ O diagnóstico definitivo, seja em pacientes com sintomas característicos e dosagens de ALA e PBG aumentadas ou em parentes de primeiro grau dos mesmos, é realizado pela pesquisa do gene mutante através de teste genético molecular, com uma capacidade de detecção do gene mutante superior a $98 \%$. $^{(1)}$

O diagnóstico diferencial da PAI deve incluir, além das óbvias patologias neuropsiquiátricas e causas habituais de dores abdominais em crises, as doenças que causam elevação do ácido delta-aminolevulínico. Destacam-se: intoxicaçáo por chumbo (saturnismo) - que leva a um quadro semelhante à da porfiria, mas de origem adquirida - e a tirosinemia hereditária.

As crises de PAI podem levar a complicaçôes severas como parada respiratória por acometimento do bulbo, quadriplegia e dor neuropática crônica nas extremidades com acometimento motor bem como dor crônica no sistema digestivo após repetidas crises, depressão e até suicídio por distúrbio psiquiátrico. ${ }^{(1,6)}$ Outras complicaçóes, geralmente pouco citadas, são hipertensão arterial crônica, insuficiência renal - que pode ocorrer por mecanismo ainda não esclarecido, e o hepatocarcinoma..$^{(7-10)}$

O tratamento das crises consiste em reduzir a dor, náuseas e vômitos com drogas consideradas seguras, suspender medicamentos porfirinogênicos (Quadro 2) álcool e tabaco, fornecer um aporte elevado de glicose com dieta rica em carboidratos e infusão de glicose hipertônica, de acordo com a gravidade dos sintomas. A necessidade de se instituírem medidas de suporte, tais como: correção de hiponatremia, hipo/hipertensão e suporte ventilatório (paralisia bulbar) varia conforme a gravidade do quadro. A terapia com hematina (Estados Unidos) ou arginato de heme (Europa) quando disponível deve ser iniciada o mais precocemente possível. Estes medicamentos inibem a ação da primeira enzima da via de síntese do heme, bloqueando a produção e acúmulo das porfirinas. No caso descrito, esta terapêutica não foi instituída, pois estas drogas não são facilmente disponíveis no mercado brasileiro. A paciente apresentou boa evolução apenas com a retirada de medicamentos porfirinogênicos e especialmente com a dieta rica 
em carboidratos. É de se pensar que, se o tratamento com hematina ou arginato do heme estivesse disponível a mesma poderia ter se beneficiado com melhora clínica mais rápida, redução do tempo e dos custos da internação hospitalar, porém pudemos demonstrar que é possível realizar uma terapêutica eficaz mesmo sem dispor de medicaçáo de tão alto custo e difícil acesso. Isto não exclui a necessidade do uso da medicação, mas confere uma alternativa eficaz de início do tratamento até disponibilização desta.

Quadro 2. Medicamentos seguros e contra-indicados para portadores de porfiria aguda $4,5,12$

\begin{tabular}{|ll|}
\hline Contra-indicados & Seguros \\
\hline Ácido valproico & Acetaminofen \\
Àlcool & Analgésicos narcóticos \\
Barbitúricos & Aspirina \\
Bloqueador de canais de cálcio & Atropina \\
Carbamazepina & Betabloqueadores \\
Carisoprodol & Bromides \\
Clonazepam (altas doses) & Cimetidina \\
Danazol & Clorpromazina \\
Diclofenaco & Diazepam \\
Ergots & Eritropoetina \\
Estrogênio & Estreptomicina \\
Fenitoína & Fenotiazinas \\
Griseofulvina & Gabapentina \\
Pirazinamida & Glicocorticóides \\
Progesterona & Hidrato de cloral \\
Rifampicina & Inibidores da recaptaçáo de se- \\
Sulfonamidas & rotonina (anti-depressivos) \\
& Insulina \\
& Penicilina e derivados \\
\hline
\end{tabular}

Fonte: Traduzido e adaptado de: Anderson KE, Bloomer JR, Bonkovsky HL, Kushner JP, Pierach CA, Pimstone NR, Desnick RJ. Recommendations for the diagnosis and treatment of the acute porphyrias. Ann Intern Med. 2005;142(6):439-50. Erratum in: Ann Intern Med. 2005;143(4):316.

American Porphyria Foundation [Internet]. PAI, CPH, PV e PAD. [cited 2008 Apr 20]. Available from:<http://www.porphyriafoundatiom. com/Portuguese/for_physicians-p/index.html>

American Porphyria Foundation. Drugs and porphyria. Drugs considered unsafe and safe in acute porphyrias [Internet]. Houston: American Porphyria Foundtion; c2007. [cited 2008 Apr 2]. Available from: http:// www.porphyriafoundation.com/about_por/drugs/drugs02.html.

Atualmente, com o auxílio da Associação Brasileira de Porfiria (ABRAPO), fundada em 2006, o acesso ao diagnóstico e terapêutica tornou-se algo menos trabalhoso. ${ }^{(11)}$

Com os cuidados adequados tem se prevenido $60 \%$ dos ataques agudos em pacientes previamente sintomáti- cos e 95\% daqueles com PAI assintomática. Atualmente o risco de morrer em um ataque agudo é pequeno, a menos que o quadro de PAI não seja diagnosticado e a exposição a fatores precipitantes se mantenha a mortalidade esta em torno de 10 a 40\%. Embora muitos pacientes com PAI levem vida normal e raramente tenham crises, outras doenças como hipertensão, insuficiência renal crônica e hepatocarcinoma podem acometê-los sendo recomendável acompanhamento médico. Cerca de $10 \%$ dos pacientes com PAI morrem devido a hepatocarcinoma. ${ }^{(4)}$

A prevenção de novas crises é tão importante quanto o diagnóstico e tratamento precoce, evitando complicaçóes. Para isto se faz necessário acompanhamento médico periódico associado a medidas simples como manter uma dieta adequada, evitar drogas porfirinogênicas, álcool, tabaco, atividade física extenuante e stress. Como o risco de suicídio é alto, recomenda-se tratamento psiquiátrico se houver sinais de depressão. Deve-se monitorar adequadamente a pressão arterial, pois a hipertensão prolongada acelera e aumenta o risco de doença renal. ${ }^{(7)}$ Como há risco muito aumentado de surgimento de hepatocarcinoma, recomenda-se a realizaçáo de exames periódicos semelhantes ao rastreamento realizado rotineiramente em portadores de cirrose. ${ }^{(8,9)}$ Em portadores que utilizam freqüentemente a hematina, recomenda-se a dosagem periódica de ferritina no sangue, pois a medicação tem grande concentraçáo de ferro e seu uso pode levar a hemocromatose secundária. É importante testar todos os parentes de pacientes com porfiria para verificar a existência do defeito genético e assim, iniciar as precauçóes, evitando tornarem-se doentes de porfiria. Mesmo os parentes que nunca tiveram sintomas devem ser testados, já que a doença pode permanecer latente em uma parcela significativa de portadores.

\section{CONCLUSÃO}

Deve-se incluir a porfiria aguda intermitente no diagnóstico diferencial de distúrbios neurológicos, psiquiátricos e gastroenterológicos em crises, no qual todos os demais exames estejam normais. Atenção deve ser dada a pacientes submetidos à cirurgias, em especial cirurgia bariátrica que, além do estresse cirúrgico, limita substancialmente a ingesta calórica podendo desencadear crises.

\section{ABSTRACT}

Acute intermittent porphyria is an unusual pathology with potentially severe consequences when not early detected. Among the possible causes of porphyric crises decrease of caloric intake has been described. A case of acute intermittent porphyria in the late postoperative period of a bariatric surgery performed for treatment of obesity is reported. A review of the diagnostic 
aspects and management of this pathology in the intensive care unit follows. A 31 year old woman was admitted in the intensive care unit three weeks after a bariatric surgery, with decreased level of consciousness and respiratory distress. The patient evolved with psychomotor agitation, mental confusion, abdominal pain and proximal tetraparesis. Diagnosis investigation disclosed severe hyponatremia $(92 \mathrm{mEq} / \mathrm{L})$, hypomagnesemia, hypophosfatemia and hypocalcemia and cloudy urine without hematuria. Acute porphyria was suspected and the urine test detected high delta amino-levulinic acid and porphobilinogen. Treatment consisted of a correction of electrolyte disturbances and high carbohydrate intake. Hematin and heme arginate were not used, due to the difficulty to acquire the medication. After 8 months the patient progressed with full recovery of muscle strength and a clinical im- provement. Acute intermittent porphyria has signs and symptoms common to several clinical, neurological, psychiatric and gastroenterological pathologies, which complicate diagnosis. Therefore, acute intermittent porphyria should be included in the differential diagnosis of neurological, psychiatric and gastroenterological alterations when results of all other exams are normal. Attention must be given to patients undergoing surgery mainly bariatric that, in addition to procedure stress, substantially limit the total caloric intake, potentially triggering crises. Review of literature did not disclose any report of acute intermittent porphyria crisis induced by bariatric surgery.

Keywords: Porphyria, acute intermittent/diagnosis; Hyponatremia; Bariatric surgery

\section{REFERÊNCIAS}

1. Jorge SG. Porfirias hepáticas [Internet]. Hepcentro; 2007. [citado 2008 Abr 20]. Disponível em:<http://www.hepcentro.com.br/porfiria.htm>

2. Tishler PV, Woodward B, O'Connor J, Holbrook DA, Seidman LJ, Hallett M, Knighton DJ. High prevalence of intermittent acute porphyria in a psychiatric patient population. Am J Psychiatry. 1985;142(12):1430-6

3. Kauppinen R. Porphyrias. Lancet. 2005;365(9455): 241-52. Comment in: Lancet. 2005;365(9463):937. Lancet. 2005;365(9463):937-8.

4. Anderson KE, Bloomer JR, Bonkovsky HL, Kushner JP, Pierach CA, Pimstone NR, Desnick RJ. Recommendations for the diagnosis and treatment of the acute porphyrias. Ann Intern Med. 2005;142(6):439-50. Erratum in: Ann Intern Med. 2005;143(4):316.

5. American Porphyria Foundation [ Internet]. PAI, CPH, PV e PAD. [cited 2008 Apr 20]. Available from:<http:// www.porphyriafoundatiom.com/Portuguese/for_physicians-p/index.html>

6. Jeans JB, Savik K, Gross CR, Weimer MK, Bossenmaier IC, Pierach CA, Bloomer JR. Mortality in patients with acute intermittent porphyria requiring hospita- lization: a United States case series. Am J Med Genet. 1996;65(4):269-73.

7. Church SE, McColl KE, Moore MR, Youngs GR. Hypertension and renal impairment as complications of acute porphyria. Nephrol Dial Transplant. 1992;7(10):986-90.

8. Lithner F, Wetterberg L. Hepatocellular carcinoma in patients with acute intermittent porphyria. Acta Med Scand.1984;215(3):271-4.

9. Andersson C, Bjersing L, Lithner F. The epidemiology of hepatocellular carcinoma in patients with acute intermittent porphyria. J Intern Med. 1996;240(4):195-201.

10. Onuki J, Teixeira PC, Medeiros MHG, Di Mascio P. DNA damage induced by 5 -aminolevulinic acid: a possible association with the development of hepatocellular carcinoma in acute intermittent porphyria patients. Quím Nova. 2002;25(4):594-608.

11. Associação Brasileira de Porfiria. ABRAPO [Internet]. Curitiba: ABRAPO; c2006. [citado 2008 Abr 10]. Disponível em: <http://www.porfiria.org.br/>.

12. American Porphyria Foundation. Drugs and porphyria. Drugs considered unsafe and safe in acute porphyrias [Internet]. Houston: American Porphyria Foundtion; c2007. [cited 2008 Apr 2]. Available from: http://www.porphyriafoundation.com/about_por/drugs/drugs02.html 